Brit. Heart f., 1967, 29, 505.

\title{
Intracavitary Potentials in Type B Ventricular Pre-excitation
}

\author{
HAMISH WATSON AND K. G. LOWE \\ From the Department of Medicine in the University of St. Andrews, Queen's College, and the Cardiac Department,
} Royal Infirmary, Dundee

In 1945, Rosenbaum and his associates proposed that ventricular pre-excitation should be classified into two types (A and B) according to the configuration of the QRS complexes in the right præcordial leads of the scalar electrocardiogram. In type A pre-excitation the delta wave is positive and the $S$ waves are small or absent; in type B the delta wave is negative and the $S$ waves are large. Though somewhat arbitrary, in that occasional cases are difficult to classify because the delta wave and main deflection are of opposite polarity (Rosenbaum, 1957; Tranchesi et al., 1959), this classification has served a useful purpose by suggesting that there are two common sites from which premature excitation of the ventricles may occur, and its value has been broadly confirmed by subsequent vectorcardiographic studies.

Bleifer et al. (1959), for example, showed in a series of 38 cases that the delta vectors and QRS sE loops in the horizontal plane fell into two groups that corresponded to Rosenbaum's types $A$ and $B$. In group $A$, the delta wave was upright in both the right and left precordial scalar leads, and in the horizontal plane vectorcardiogram the delta vector and the QRS sE loops were orientated anteriorly between $+30^{\circ}$ and $+120^{\circ}$. In group $B$, the delta wave was negative in the right præcordial leads and the delta vector and $\mathrm{QRS} \mathrm{sE}$ loops were orientated to the left between $-60^{\circ}$ and $+30^{\circ}$ in the horizontal plane. In general, the angle between the delta vector and the $Q R S$ sE loop was narrow, indicating that the delta wave appeared to determine the direction of the remaining portion of the QRS $\mathrm{sE}$ loop.

Tranchesi et al. (1959) have also made a vectorial analysis, classifying 27 cases into types I and II, according to the orientation of the delta vector. In type I the delta wave was positive in V2 and the

Received August 10, 1966. delta vector orientated anteriorly in the horizontal plane between $+10^{\circ}$ and $+160^{\circ}$ (average $51 \cdot 1^{\circ}$ ). In type II the delta wave was negative in V2 and the delta vector was orientated posteriorly in the horizontal plane between $-5^{\circ}$ and $-20^{\circ}$ (average $-12^{\circ}$ ). In their cases of type I pre-excitation, with deep $S$ waves in the right præcordial scalar leads that would be difficult to place in Rosenbaum's classification, there was commonly left ventricular overloading to account for the backward orientation of $s \hat{A} \mathrm{QRS}$.

Provided that classification is based only upon the orientation of the delta vector, Tranchesi's types I and II can therefore be equated with Rosenbaum's types $A$ and $B$.

Tranchesi and his colleagues presumed that in type I or A the area of pre-excitation was in the postero-basal regions of the septum and the adjacent areas of the ventricular walls, and that in type II or $B$ it was in the right anterior aspect of the septum and the anterior wall of the right ventricle. Though inconclusive, most of the evidence from scalar and vector electrocardiography now suggests that type $\mathrm{B}$ is right ventricular pre-excitation, but it is still uncertain which ventricle is prematurely excited in type A.

Vectorial analysis does not by itself provide the answer and intracardiac potentials have been studied by various workers in an attempt to localize the sites of ventricular pre-excitation with greater accuracy (Sodi-Pallares et al., 1948; Grishman, Kroop, and Steinberg, 1950; Hecht and Ritzmann, 1950; Coelho et al., 1951a, b; Sodi-Pallares, 1956; Hecht, 1957; Latour and Puech, 1957; Gamboa et al., 1962). These studies, however, have been largely confined to the right heart and very few intracardiac electrocardiograms have been recorded from the left side of the heart (Coelho et al., 1951b; SodiPallares, 1956). 


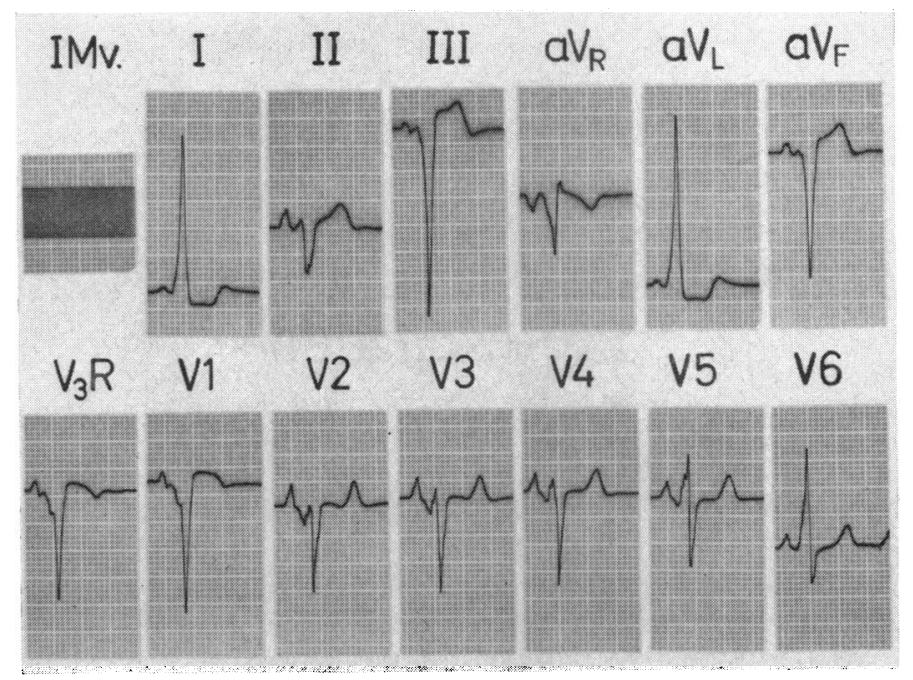

FIG. 1.-A.B., boy aged 12 years. Scalar electrocardiogram showing type B ventricular pre-excitation with negative delta waves in leads V3R and V1.

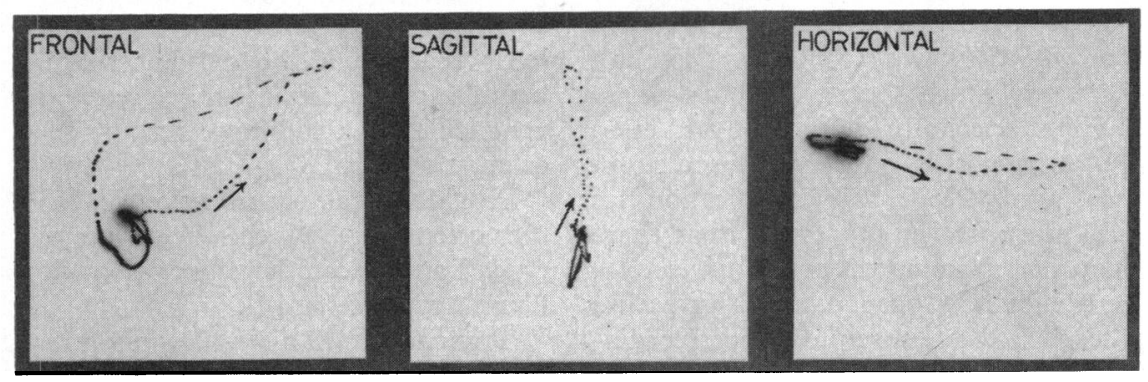

Fig. 2.-Vectorcardiogram from same patient using cube system (Grishman, Borun, and Jaffe,1951). Time marking is at $2.5 \mathrm{msec}$. intervals. Note that the delta vector is inscribed very slowly to the left.

As the intracardiac electrocardiographic findings in type B ventricular pre-excitation have not hitherto been adequately documented, we are presenting a case in which intracavitary potentials were obtained from all the heart chambers, in the belief that such recordings are of importance in locating the sites of ventricular pre-excitation.

\section{INTRACARDIAC ELECTROCARDIOGRAM IN TYPE B VeNTRICULAR PRE-EXCITATION}

The patient from whom these records were obtained was a boy of 12 who had typical features of Ebstein's anomaly of the tricuspid valve, with only slight cardiomegaly. He was without symptoms, but had been known to have congenital heart disease since he was 18 months old.

The scalar and vector electrocardiograms are illustrated in Fig. 1 and 2 and show evidence of type B ventricular pre-excitation. Cardiac catheterization and cine-angiocardiography confirmed the diagnosis of Ebstein's anomaly, revealing a large atrialized right ventricular chamber, which opened into the lower end of the outflow tract. The left heart was catheterized through a small defect high in the interatrial septum.

The intracardiac electrocardiogram (Fig. 3) from an electrode at the tip of the catheter recorded tall $\mathbf{R}$ waves in the cavity of the left ventricle $(\mathrm{g})$ and the delta waves remained positive throughout withdrawal from the apex of the left ventricle into the left atrium (d). They became negative as the interatrial septum was crossed and the electrode entered the right atrium (a). When the catheter was advanced into the right ventricle the delta waves in the IEG remained negative in the atrialized por- 


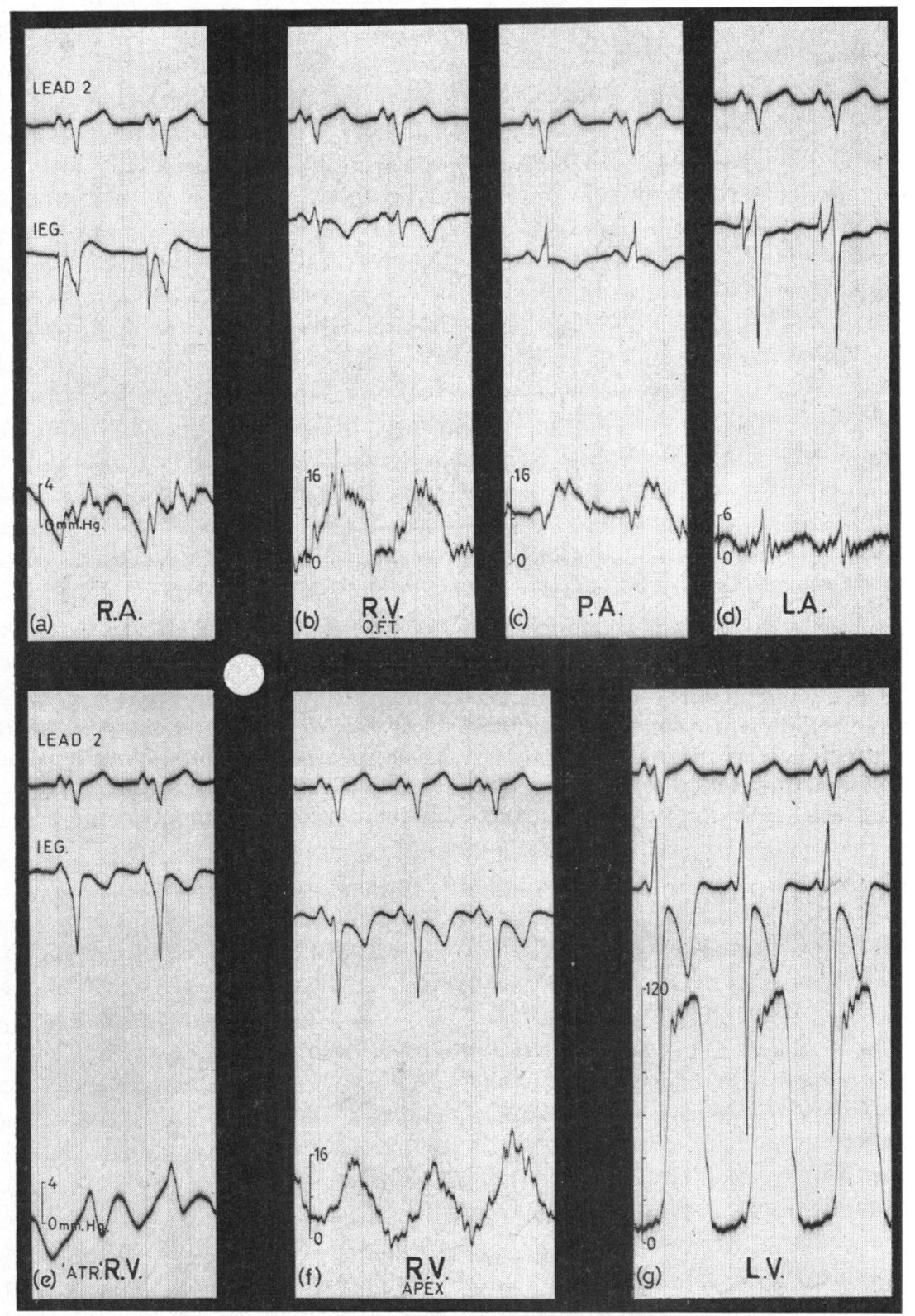

FIG. 3.-Composite diagram containing excerpts of the scalar and intracardiac (IEG) electrocardiograms, and pressure pulses recorded during cardiac catheterization. The IEG delta waves are negative in the right atrium and atrialized right ventricle; elsewhere they are positive, and the small white circle is to suggest a source of pre-excitation in the right ventricle with spread of excitation away from the right atrium and the atrialized portion of the right ventricle, and towards the other chambers (R.A. = right atrium; R.V.=right ventricle; "ATR" = atrialized; O.F.T.= outflow tract; P.A. = pulmonary artery; L.A. = left atrium; L.V.= left ventricle). 




FIG. 4.-A tracing recorded as an electrode-tipped catheter was withdrawn from the pulmonary artery into the right ventricular outflow tract. The delta wave in the IEG remains positive throughout.

tion (e), became positive only after the functioning part of the chamber was entered (f) and remained positive throughout the right ventricular outflow tract (b) and in the pulmonary artery (c).

An example of the persistence of positive delta waves upon withdrawal from the pulmonary trunk through the pulmonary valve and into the infundibulum is illustrated in Fig. 4, and the change from a positive delta wave at the apex of the right ventricle to a negative one in its atrialized portion is seen in Fig. 5. All complexes observed or recorded in the outflow tract or near the apex of the right



FIG. 5.-Withdrawal tracing from the apex of the right ventricle in which the positive delta wave becomes negative as the electrode passes back through the orifice of the abnormal tricuspid valve into the atrialized portion of the chamber. 


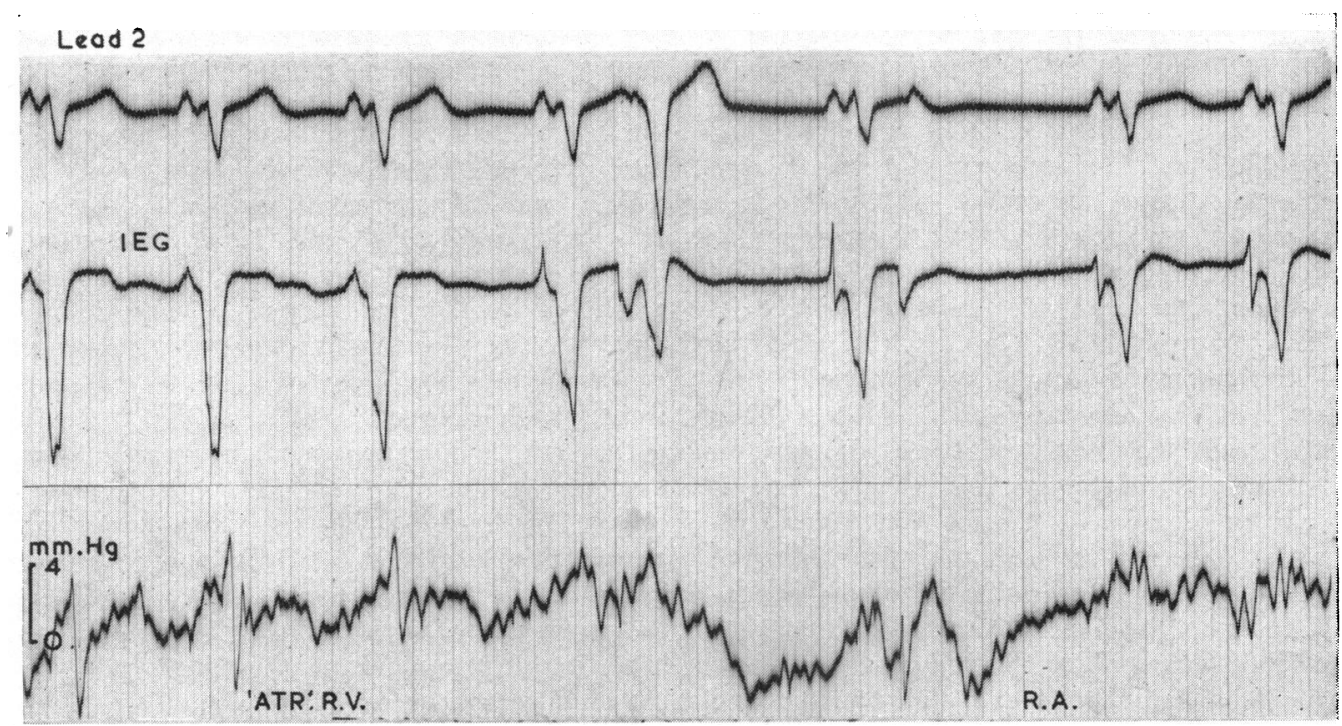

FIG. 6.-The delta wave remains negative throughout withdrawal from the atrialized portion of the right ventricle into the right atrium. The polarity of the $\mathbf{P}$ wave is reversed in the nodal ectopic beat.

ventricle showed such positive delta waves, and the transition from positive to negative was nearly always synchronous with the change from a ventricular to atrial type right ventricular pressure pulse. On one occasion only, the first few complexes recorded in the atrialized chamber had small initial $\mathbf{r}$ waves.

Multiple withdrawals from the atrialized portion of the right ventricle into the right atrium proper, on the other hand, were all of the type seen in Fig. 6 where all the delta waves are negative. This transition from a positive to a negative delta wave in the region of the outlet from the displaced tricuspid valve indicates that the site of pre-excitation is somewhere between the true $\mathrm{A}-\mathrm{V}$ annulus and the apex of the right ventricle, but it is too difficult to be certain of the position of the catheter tip-even with biplane screening (Watson, 1966)-to be more precise about its exact position in the right ventricular wall.

\section{Discussion}

Sodi-Pallares and his colleagues obtained intracardiac records from the right side of the heart in 6 cases (2 type A and 4 type B) and reported exclusively negative complexes of QS configuration in the pulmonary conus region for type $A$ and near the tricuspid valve for type $B$. These were thought to correspond to areas of pre-excitation located in the septum or in other nearby parts of the free walls of the ventricles (Sodi-Pallares et al., 1948; SodiPallares, 1956). Their intracardiac recordings were criticized by Grishman et al. (1950) on the grounds that some of the electrocardiograms, thought to have been recorded in the right ventricle, had morphology suggestive of coronary sinus tracings, and that in other recordings the catheter had not passed through the tricuspid valve. In their own studies Grishman et al. recorded intracardiac potentials from the right side of the heart in 7 cases and found positive delta waves followed by $\mathrm{rS}$ at the tricuspid valve region and positive delta waves continuing into $R, R^{\prime}$, or $r R^{\prime}$ in the right ventricle. After correlating these findings with scalar and œesophageal leads they repudiated Rosenbaum's 1945 classification, because it seemed to them that the excitation wave from the atria passed along accessory muscular pathways to reach the posterior aspect of the left ventricle and the anterior aspect of the right ventricle simultaneously. Coelho and his colleagues (1951a) recorded intracardiac leads from the right heart in 4 cases ( 1 type A, 1 "intermediate", and 2 type $B$ ) and from the left ventricle in 1 case (type A). In type A pre-excitation, the right ventricular complexes were RS and the left ventricular complex QS.

Right heart endocardial leads were also recorded by Hecht (Hecht and Ritzmann, 1950; Hecht, 1957), who found in type A pre-excitation "some of the characteristics of right bundle-branch block in the endocardial leads indicating that excitation of the 
right ventricle follows that of the left". In type B, wide QS complexes showing the region of early excitation were recorded just inside the tricuspid valve close to the upper portion of the ventricular septum. He concluded that type A was "compatible with advance excitation of basilar septal areas of the left ventricle, and type B is compatible with that from the right side".

Latour and Puech (1957) found positive delta waves throughout the right ventricle, suggesting left-to-right transseptal excitation in type A preexcitation, and Coelho's findings in type A (QS in left ventricle and $R S$ in right ventricle) also support left-to-right septal activation. In type B, Latour and Puech found the earliest right ventricular excitation and QS complexes near the tricuspid valve and suggested that this was the site of pre-excitation. Deeper in the ventricle the morphology of the complexes changed to $\mathrm{rS}$, and in the outflow tract to RS. Throughout the right atrium the ventricular complex was negative $(\mathrm{QS})$ with a slow initial inscription. Latour and Puech (1957), like Hecht (1957), accept that type A is left ventricular pre-excitation and type $\mathrm{B}$ is right ventricular preexcitation. This is at variance with Sodi-Pallares (1956) who considers both type A and type B to be right ventricular in origin, though occurring at different sites in that chamber. Sodi-Pallares compared and contrasted pre-excitation with incomplete left bundle-branch block and published scalar electrocardiograms from a case of mitral and aortic valve disease in which it was difficult to differentiate between type B pre-excitation and incomplete left bundle-branch block. In this case intracardiac electrocardiograms recorded in the left ventricle showed $\mathrm{rS}$ complexes. He also studied two cases of type A pre-excitation in which both right and left ventricular tracings were recorded, and stated that RS complexes were recorded at some sites in both ventricles; these, however, were not illustrated.

There is still disagreement, therefore, about the exact sites of ventricular pre-excitation, and controversy about the patterns of the intracardiac electrocardiograms; particularly about those recorded in the ventricles. This will continue until such cases are fully documented and multiple records obtained from all four chambers of the heart. In this way the sites of pre-excitation can be identified by the precocious negative delta waves showing the spread of premature ventricular excitation away from the exploring electrode. In our case of type $B$ pre-excitation the spread of excitation is seen to be from right to left ventricle ( $Q S$ in right ventricle and RS in left ventricle). This is in contrast to the case illustrated by Coelho and his colleagues (1951a) in which type A pre-excitation was associated with spread of excitation from left to right ventricle (QS in left ventricle and $R S$ in right ventricle).

While it is unlikely that intracardiac electrocardiographic recordings can locate accurately the site of pre-excitation, we would agree with Hecht (1957), and Latour and Puech (1957), that type A is left and type $\mathrm{B}$ is right ventricular pre-excitation; a view that is based not only on consideration of all the published intracardiac electrocardiograms, but also on two other pieces of evidence that seem significant. First, when Gamboa et al. (1962) induced right bundle-branch block (RBBB) in two patients with type A pre-excitation by manipulating a catheter in the right ventricle, they were able to obtain simultaneous features of pre-excitation and an advanced degree of RBBB in the electrocardiogram and vectorcardiogram. This suggested that the prematurely activated muscular area was located in the left ventricle and that the right bundle-branch block delayed right ventricular activation. By contrast, in a patient with intermittent type B preexcitation, RBBB could only be induced in normally conducted complexes that did not show pre-excitation. Gamboa therefore postulated that type B pre-excitation was a right ventricular phenomenon that depolarized most of the right ventricular muscle. This is not universally true, however, as coexistent $\mathrm{RBBB}$ and type $\mathrm{B}$ pre-excitation have been demonstrated by Robertson et al. (1963).

The other evidence supporting the view that type $\mathrm{A}$ is left and type B is right ventricular pre-excitation is provided by a study of Ebstein's anomaly of the tricuspid valve. In this condition where right ventricular anatomy is deranged and where one might reasonably expect some abnormality of conduction in the right ventricle, just under 10 per cent of cases have type B ventricular pre-excitation (Frau and Agostoni, 1959). Moreover, in corrected transposition with ventricular inversion, the tricuspid atrio-ventricular valve is sometimes the site of an Ebstein-like lesion. This left-sided Ebstein's anomaly may also be associated with ventricular pre-excitation, but because it is now the left or systemic ventricle whose anatomy is disturbed, the pre-excitation is type A (Schiebler et al., 1961).

\section{SUMMARY}

The classification of ventricular pre-excitation has been discussed and the electrocardiographic evidence of the sites of pre-excitation has been reviewed.

Intracardiac electrocardiograms of type B ventricular pre-excitation are presented from all four heart chambers in a boy with Ebstein's anomaly of the tricuspid valve. 
These confirm that early activation spreads from right to left ventricle in contrast with previous evidence of spread from left to right in type A preexcitation, supporting the majority view that type $A$ is left ventricular and type B right ventricular preexcitation.

We wish to thank Dr. Patrick MacArthur for referring this interesting case.

\section{REFERENCES}

Bleifer, S., Kahn, M., Grishman, A., and Donoso, E. (1959). Wolff-Parkinson-White syndrome. A vectorcardiographic, electrocardiographic and clinical study. Amer. f. Cardiol., 4, 321.

Coelho, E., Fonseca, J. M., Borges, A. S., Nunes, A., and Paiva, E. (1951a). Étude des dérivations intra-cavitaires du syndrome de Wolff-Parkinson-White et son déclenchement au moyen de l'excitation de la cloisen inter-ventriculaire. Sem. Hôp. Paris, 27, 8.

,-- , Nunes, A., Padua, F., and Serras Pereira, J. (1951b). Les potentiels intracavitaires du cour gauche de l'homme dans différentes cardiopathies. Arch. Mal. Cour, 44, 961.

Frau, G., and Agostoni, A. (1959). L'elettrocardiogramma nella malattia di Ebstein. Morfologia, genesi ed importanza diagnostica. Descrizioni di 2 nuovi casi e rassegna di altri 124 casi riportati nella letteratura. Folia cardiol. (Milano), 18, 223.

Gamboa, R., Peñaloza, D., Sime, F., and Banchero, N. (1962). The role of the right and left ventricles in the ventricular pre-excitation (WPW) syndrome. An experimental study in man. Amer. F. Cardiol., 10, 650.

Grishman, A., Borun, E. R., and Jaffe, H. L. (1951). Spatial vectorcardiography: Technique for the simultaneous recording of the frontal, sagittal and horizontal projections. Amer. Heart f., 41, 483.

- -, Kroop, I. G., and Steinberg, M. F. (1950). The course of the excitation wave in patients with electrocardiograms showing short P-R intervals and wide QRS complexes (Wolff-Parkinson-White syndrome). Amer. Heart F., 40, 554.

Hecht, H. H. (1957). Anomalous atrioventricular excitation. Further observations on the spread of ventricular excitation. Ann. N.Y. Acad. Sci., 65, 841.

- and Ritzmann, L. (1950). Potential variations of the epicardial and endocardial surfaces in anomalous atrioventricular excitation. Amer. F. Med., 8, 527.

Latour, H., and Puech, P. (1957). Électrocardiographie Endocavitaire. Masson, Paris.

Robertson, P. G. C., Emslie-Smith, D., Lowe, K. G., and Watson, H. (1963). The association of type B ventricular pre-excitation and right bundle-branch block. Brit. Heart F., 25, 755.

Rosenbaum, F. F. (1957). Anomalous atrioventricular excitation. Electrocardiographic analysis. Ann. N.Y. Acad. Sci., 65, 832.

—, Hecht, H. H., Wilson, F. N., and Johnston, F. D. (1945). The potential variations of the thorax and the esophagus in anomalous atrioventricular excitation (Wolff-Parkinson-White syndrome). Amer. Heart f., 29, 281.

Schiebler, G. L., Edwards, J. E., Burchell, H. B., DuShane, J. W., Ongley, P. A., and Wood, E. H. (1961). Congenital corrected transposition of the great vessels: a study of 33 cases. Pediatrics, 27, 851.

Sodi-Pallares, D. (1956). New Bases of Electrocardiography. (Henry Kimpton, London.) Mosby, St. Louis.

—, Soberón, J., Thomsen, P., Fishleder, B. L., and Estandia, A. (1948). Contribucion al estudio del sindrome de Wolff-Parkinson-White por las derivaciones intracavitarias. Arch. Inst. Cardiol. Méx., 18, 1.

Tranchesi, J., Guimarães, A. C., Teixeira, V., and Pileggi, F. (1959). Vectorial interpretation of the ventricular complex in Wolff-Parkinson-White syndrome. Amer. $\mathcal{F}$. Cardiol., 4, 334.

Watson, H. (1966). Electrode catheters and the diagnosis of Ebstein's anomaly of the tricuspid valve. Brit. Heart f., 28, 161. 